\title{
Synergic Role of Dexamethasone And Lianhua Qingwen Capsule Accelerate Nucleic Acid Negative Conversion In Severe COVID-19 Patients
}

\author{
Xin Fang ( 15972021296@163.com ) \\ Huazhong University of Science and Technology https://orcid.org/0000-0002-3871-8128 \\ Meng'en Zhu \\ Huazhong University of Science and Technology \\ Kemeng Zhang \\ Huazhong University of Science and Technology \\ Zhaohui Wang \\ Huazhong University of Science and Technology \\ Ping He \\ Huazhong University of Science and Technology
}

\section{Research}

Keywords: COVID-19, SARS-CoV-2, nucleic acid negative conversion, dexamethasone, Lianhua Qingwen Capsule Posted Date: October 12th, 2021

DOI: https://doi.org/10.21203/rs.3.rs-955194/v1

License: @) (i) This work is licensed under a Creative Commons Attribution 4.0 International License. Read Full License 


\section{Abstract}

Background:Corticosteroids were recommended by guidelines in severe or critical COVID -19 patients likely to have acute respiratory distress syndrome. In the treatment strategies of COVID - 19 in China, corticosteroids were generally combined with some traditional Chinese medicine, especially Lianhua Qingwen Capsule (LHQW). We aimed to investigate the correlation between dexamethasone with or without LHQW and the nucleic acid negative conversion in severe patients with COVID-19.

Methods:The clinical course and nucleic acid negative conversion time of 452 consecutive symptomatic COVID-19 patients admitted to the west campus of Union Hospital in Wuhan from January 31, 2020, to March 13, 2020, were evaluated retrospectively.

Results:The duration of virus RNA from positive to negative in the participants was 28 days (interquartile range 2134 days). Of the 452 patients, 105 (23.23\%) subjects received dexamethasone, and 347 (76.77\%) did not. Among patients receiving LHQW treatment, the nucleic acid negative conversion time in the dexamethasone group was shorter than that in the no dexamethasone group $(\beta,-4.77 ; 95 \% \mathrm{Cl},-9.41,-0.12)$. Although among those who were receiving no LHQW treatment, the effect on shortening nucleic acid negative conversion time of dexamethasone was not observed $(\beta, 5.37 ; 95 \% \mathrm{Cl},-4.88,15.62 ; \mathrm{p}$ interaction $=0.038)$. Additional multivariable propensity-score analyses yielded consistent results with the unmatched participants $(\beta,-8.61 ; 95 \% \mathrm{Cl},-16.73,-0.50)$.

Conclusions $\mathbb{X}$ In patients hospitalized with COVID-19, the use of dexamethasone resulted in shortening nucleic acid negative conversion time among those who were receiving LHQW, suggesting that LHQW synergic with dexamethasone accelerated the SARS-CoV-2 clearance in severe patients.

Trial registration囚ECUH 2020-0212, a retrospective study.

\section{Summary}

The present study indicated that dexamethasone synergic with LHQW accelerated the SARS-CoV-2 clearance in severe patients.

\section{Introduction}

The coronavirus disease 2019 (COVID-19) was caused by severe acute respiratory syndrome coronavirus 2 (SARSCoV-2). It has affected more than two hundred million patients globally. The diagnosis of COVID-19 is usually determined by a positive result of the viral nucleic acid test (NAT) from routine nasopharyngeal/ pharyngeal swab specimens, sometimes other body fluids, secretions, and excreta[1, 2]. All patients with positive viral RNA detection need to be isolated. According to "Diagnosis and Treatment Scheme of New Coronavirus Infected Pneumonia" (sixth edition)issued by the National Health Commission[3], after the relief of symptoms and two successive (minimum 24h sampling interval) negative viral nucleic acid results for respiratory specimens, the isolated cases can be disisolated. Therefore, one of the crucial factors evaluating management effectiveness is whether the management accelerates the conversion time of the virus nucleic acids from positive to negative.

Many severely ill patients with the pandemic rapidly progressed to acute respiratory distress syndrome (ARDS) and multiple organ failure resulting in death within a short time[4]. Cytokine storm is one of the underlying mechanisms of ARDS and multiple organ failure, and it is critical in deteriorate process of COVID-19 patients. Therefore, 
effectively suppressing the cytokine storm is essential to prevent illness exacerbation in patients with COVID-19 infection.

Corticosteroids as a solid anti-inflammatory therapy have been widely used to treat severe acute respiratory syndrome and the Middle East respiratory syndrome. In contrast, the role of corticosteroids for COVID-19 remains debated. Whether corticosteroids involve prolonged virus duration is one of the major controversies $[5,6][5,6]$. To date, it has been reported that corticosteroid therapy for critically ill patients with Middle East Respiratory syndrome was associated with delayed MERS coronavirus RNA clearance[5]. Two studies from China have found that the duration of viral RNA detection in the corticosteroid treatment group was longer than that in the non- corticosteroid treatment group, while they failed or didn't show corticosteroid was an independent risk factor of prolonged viral RNA shedding $[7,8]$. The other two retrospective studies were from Beijing ( $n=66$, non-severely ill patients 69.69\%), and one was from Guangzhou ( $n=267$, non-severely ill patients $83.5 \%)$, China. Both concluded that corticosteroids were significantly and independently associated with prolonged viral RNA shedding[9] [10]. On the contrary, two retrospective studies from Wuhan ( $n=173,84.4 \%$ non-severely ill patients) $[11,12]$ and Kunming ( $n=33,100 \%$ nonseverely ill patients) [12], China, exhibited that corticosteroid therapy did not prolong the duration of nucleic acid negative conversion.

In fact, clinical evidence supports a low-dose and short-term corticosteroid prescribed in severe and critical COVID19 patients likely to have acute respiratory distress syndrome[13,14]. Moreover, the treatment strategies currently for COVID-19 include antiviral, antibiotic, immunoenhancement, and traditional Chinese medicine in China[3]. Traditional Chinese medicine, including LHQW, was reported remarkably effective for treating patients with COVID19[15]. To date, there is uncertainly about the effect of corticosteroids with or without LHQW on the viral clearance time in severe patients.

The present study focused on severe patients to explore an essential association between corticosteroid alone or in combination with LHQW and nucleic acid negative conversion time. Further, we analyzed unmatched and matched subjects to exclude potential confounding factors.

\section{Method}

\section{Study Design and Participants}

This was a retrospective study of consecutive patients with COVID-19 who were admitted to the west campus of Union Hospital in Wuhan between January 31, 2020, and March 13, 2020. The hospital was responsible for accepting COVID-19 confirmed cases in the Wuhan area. All patients were unselective who were unified arranged by the Chinese Government from the whole city of Wuhan. All confirmed COVID-19 cases were isolated until viral RNA tests were negative at least twice sequentially. The study was approved by the Ethics Committee of Union Hospital, Tongji Medical College, Huazhong University of Science and Technology (ECUH 2020-0212). The requirement for informed consent was waived.

COVID-19 infection was confirmed by positive SARS-CoV-2 RNA test from throat swab samples, using a reverse transcription-quantitative PCR method according to the published standard protocols from the National Health Commission of the People's Republic of China (Sixth Edition) [7]. The disease severity at admission was also assessed according to published standard protocols from the National Health Commission of the People's Republic of China (Sixth Edition) [3]. Shortly, severe patients were individuals who have means oxygen saturation $\leq 93 \%$ in the resting state on room air at sea level, arterial partial pressure of oxygen to fraction of inspired oxygen 
$(\mathrm{PaO} 2 / \mathrm{FiO} 2) \leq 300 \mathrm{mmHg}(1 \mathrm{mmHg}=0.133 \mathrm{kPa})$. Respiratory distress, respiratory rate $\geq 30 \mathrm{beats} / \mathrm{min}$, or lung infiltrates $\geq 50 \%$. We excluded COVID-19 patients who had an unclear history of illness onset of the disease.

\section{Procedure}

It was recorded that a series of NAT results from routine pharyngeal swab specimens during hospitalization for each patient every other day. The clinical features, laboratory tests, and chest CT imagines at admission were also recorded, and so was management during hospitalization. The nucleic acid negative conversion time was calculated from illness onset to negative NAT. Two physicians checked all data.

\section{Statistical Analysis}

All analyses were performed using Empower (R) (www.empowerstats.com, X\&Y solutions, inc. Boston MA) and R (http://www.R-project.org). Firstly, we describe the demographic characteristics and biochemical values in patients treated with corticosteroids and without corticosteroids. Continuous variables were presented as mean (SD) or median (IQR), and categorical variables were expressed as numbers (\%). The differences between the two groups were compared using t-tests for continuous data and Chi-squared tests for categorical variables. Kruskal-Wallis test was applied for the variables with a skewed distribution. Fisher Exact for categorical variables with Expects $<10$. Secondly, a univariate analysis model was used to examine whether corticosteroid and other factors were correlated to the nucleic acid negative conversion time. Stratification analysis was performed by factors that were screened by "Check and filter for covariables" or "interaction test." Next, we performed a multivariate piecewise linear regression model to assess the independent correlation between corticosteroid and nucleic acid negative conversion time. The confounders adjusted in the multivariate regression were on the basis of their associations with the outcomes of interest or a change in effect estimate of more than $10 \%$. Finally, given the differences in the baseline characteristics between participants in the two groups, propensity-score matching was done to identify a cohort of patients with similar baseline characteristics. Matching was formed using a 1:2 matching protocol without replacement (greedymatching algorithm). And then logistic regression analyses after matching on the propensity score in a range of \pm 0.02 . The significance level of the hypothesis tests was set at 0.05 (two-sided).

\section{Results}

\section{Baseline Characteristics of Participants in the Study}

The clinical characteristics of all patients were summarized in supplement Table 1. Among 452 COVID-19 patients, the average age was 57 years old. The number of male $(n=225,49.78 \%)$ was similar with female $(n=227$, $50.22 \%$ ). The median days lag from illness onset to hospital admission were 10 days (interquartile range, 7-15 days). The nucleic acid negative conversion time was 28 days (interquartile range 21-34 days). Common underlying concomitant diseases included hypertension (16.15\%) and diabetes (8.85\%).

On admission, all patients had had severe symptoms and received standard care, including supportive and antiviral treatment. Arbidol was the most frequently used antiviral regiments (94.91\%). $71.90 \%$ of patients received LHQW treatment (four capsules each time, three times daily for two weeks). Dexamethasone (10mg/day, 3-5 days) was used shortly to inhibit inflammatory cascade in $23.23 \%$ of patients who expressed progressing disease. Most patients (88.94\%) were treated with a single antibiotic, which generally covered common pathogens and some 
atypical pathogens; when secondary bacterial infection occurred, medication was ministered according to bacterial culture and drug sensitivity.

Since all patients with symptoms of respiratory distress, they received oxygen therapy, including nasal catheters $(98.01 \%)$, mask $(0.89 \%)$, and high-flow nasal cannula oxygen therapy $(0.22 \%)$, or non-invasive ventilator $(0.88 \%)$ on admission. $13.50 \%$ of participants were transformed from nasal catheters to mask, and $1.33 \%$ of the subjects were transferred to non- invasive-ventilator with illness worsens. As of March 13, 2020, all patients were survived and discharged.

\section{The Different Characteristics Between Patients with Dexamethasone and without Dexamethasone}

Of the 452 patients, 105 (23.23\%) subjects received dexamethasone, and 347 (76.77\%) did not. The distribution of the patients' baseline characteristics according to dexamethasone exposure was shown in Table 1, both in the unmatched and propensity-score-matched analytic samples.

There were no differences in age and sex in the unmatched patients with and those without dexamethasone. In contrast to the counterpart, however, dexamethasone-treated patients exhibited a higher percentage of other endocrine system diseases history and higher leukocytes, neutrophile granulocytes, procalcitonin, serum IL-6 levels, D-Dimer and hsTNI, but lower lymphocytes, hemoglobin, albumin at baseline $(p<0.05)$. In CT scan examination, more percentage of dexamethasone-treated patients had lung consolidation shadow. All suggested that patients with dexamethasone exhibited more severe inflection, stronger inflammatory responses, and poorer nutritional status than no dexamethasone-treated- patients. The characteristics led to more percentage of dexamethasone-treated patients receiving anti-virus and supportive management, including Remdesivir, immune globulin, thymosin, plasbumin, mask, and high flow as well as ventilator treatment, when compared those treatments to patients without dexamethasone treatment $(p<0.05)$. Although many differences were aforementioned, the viral RNA shedding had no significant differences between the two groups $(p=0.288)$.

In the matched patients, thirty-three participants were exposed to dexamethasone, and twenty-six patients were not exposed. The differences of variables between patients with dexamethasone and without dexamethasone were attenuated in the propensity-score-matched subjects compared with that in the unmatched samples.

\section{The Correlation Between Dexamethasone Combined with or without LHQW and Nucleic Acid Negative Conversion Time}

Table 2 display the association between dexamethasone and nucleic acid negative conversion time. LHQW as an interaction factor affected nucleic acid negative conversion time of patients who were exposed to dexamethasone or were not $(p=0.0273)$. Dexamethasone significantly accelerated nucleic acid negative conversion time than nodexamethasone $(\beta,-4.77 ; 95 \% \mathrm{Cl},-9.41,-0.12)$ in LHQW treated group after adjusted covariable. Corticosteroid using alone had a tendency to prolong nucleic acid negative conversion time than no-corticosteroid using patients $(\beta, 5.37$; $95 \% \mathrm{Cl},-4.88,15.62)$ in no LHQW treated group, but the result had no significant differences $(p=0.3181)$. Additional multivariable propensity-score analyses yielded consistent results with the unmatched participants (Figure 1)

\section{Discussion}

In the analysis involving severe patients who had been hospitalized with COVID-19, dexamethasone had different effects on virus conversion time in subgroups of LHQW. In LHQW treated subgroup, dexamethasone was independently associated with accelerated nucleic acid negative conversion time than the no dexamethasone 
group. While in no LHQW treated subgroup, dexamethasone was not an independent risk factor associated with prolonged virus conversion time compared to their counterpart. Even though we focused on severe patients in the present study, dexamethasone-treated patients still exhibited more robust inflammatory responses and more nutrition consumption than no dexamethasone-treated patients. That suggested that patients with dexamethasone had more severe illnesses than those without. The results are consistent with many studies about the corticosteroid on nucleic acid negative conversion time. Therefore, there is a confusing question about whether prolonged virus duration in corticosteroid-treated patients was because of severe illness or of the influence of corticosteroid medicine[7]. Furthermore, patients with corticosteroids were received more therapy in the present study. It had been reported that inappropriate inflammatory responses, albumin levels, and other medicine besides age, gender are the risk factors to prolonged viral RNA shedding[7, 16, 17]. Hence we did in matched besides in unmatched patients to exclude the potential effect factors on nucleic acid negative conversion time.

The study displayed uncertain results about the relationship between dexamethasone and nucleic acid negative conversion time in the unmatched and matched patients without LHQW. It is essential to consider how dexamethasone affected individuals' inflammatory responses since the inappropriate inflammatory response were one of the critical risk factors for the prolonged viral shedding[18, 19]. Dexamethasone can correct the strong inflammatory reactions but cannot improve the weaker inflammatory responses. Hence the different inflammatory responses affected by dexamethasone in patients led to various nucleic acid negative conversion times. That further suggested that co-treatment is essential in the management of COVID-19 patients.

Excitedly, in the study in patients with LHQW, dexamethasone was associated with accelerated viral clearance time than patients without dexamethasone. It indicated that LHQW is synergic with dexamethasone against SARS-Cov-2 in severe patients. We considered the protective role of LHQW against SARS-Cov-2 by decreasing viral load and improved inflammation. LHQW can inhibit viral replication and maturation by reducing viral load, especially at the early stage of the virus of infection. angiotensin-converting enzyme 2 (ACE2 receptor) is the cell-entry receptor for SARS-CoV-2. 3CLpro is a main viral proteinase, which controls the activities of the coronavirus replication complex[20]. The ingredients of LHQW recipes, including quercetin, kaempferol, and luteolin, can target ACE2 and 3 CLpro to affect viral replication and maturation[21]. At the same time, LHQW reduced systemic and airway inflammation by regulation of the inherent and acquired immune systems through the decrease of IL-6 levels to relieve COVID-19 symptoms[21]. However, in the present study, we failed to show that LHQW alone accelerated nucleic acid negative conversion time. That further suggested that the role of LHQW and dexamethasone complementation each other to against SARS-Cov-2. All evidence indicated that inhibition of viral replication and maturation, and correction of inappropriate immune responses to the virus at the same time on the basis of essential supportive management, may be an effective method to accelerate virus clearance in severe illness patients with COVID-19.

Our study has some limitations. First, the study had a small size. This is a retrospective and a real-world study, most percentage of patients using LHQW on admission leading to a small size of patients without LHQW in the study. Secondly, not all laboratory tests were done in all patients, including hs-cTNI, IL-6 since the differences in each patient's illness condition.

\section{Conclusions}

In summary, our study supported that corticosteroid (short-doses and short-term) and LHQW using in the early stage on the basis of essential supportive management can synergically accelerate the viral clearance time in hospitalized 
severe patients with COVID-19. The viral load and prognosis were worthy of further study.

\section{List Of Abbreviations}

Coronavirus disease 2019 (COVID-19), Severe acute respiratory syndrome coronavirus 2 (SARS-CoV-2), Viral nucleic acid test (NAT), Lianhua QingWen Capsule (LHQW), middle East Respiratory Syndrome (MERS), acute respiratory distress syndrome (ARDS), interleukin- 6 (IL-6), high sensitive troponin I (hs- TNI), angiotensin-converting enzyme 2 (ACE2 receptor)

\section{Declarations}

\section{Ethics approval and consent to participate}

The study was approved by the Ethics Committee of Union Hospital, Tongji Medical College, Huazhong University of Science and Technology (ECUH 2020-0212). The requirement for informed consent was waived.

\section{Consent to publish}

Not applicable

\section{Availability of data and materials}

The datasets used or analysed during the current study are available from the corresponding author on reasonable request.

\section{Competing interests}

Authors have no conflicts of interest or financial ties to disclose.

\section{Funding}

Not applicable

\section{Acknowledgement}

Not applicable

\section{Authors' Contributions}

Ping He conceived and designed the experiments; all authors performed the experiments; Meng'en and Kemeng Zhang collected data; Xin Fang and Meng'en analyzed the data; Xin Fang drafted the paper. Ping He and Zhaohui Wang revised the manuscript. All authors read and approved the final manuscript. The manuscript has not been submitted elsewhere.

\section{References}

1. Loeffelholz MJ, Tang YW. Laboratory diagnosis of emerging human coronavirus infections - the state of the art. Emerg Microbes Infect. 2020;9(1):747-56. https://doi.org/10.1080/22221751.2020.1745095. 
2. Gitman MR, Shaban MV, Paniz-Mondolfi AE, Sordillo EM. Laboratory Diagnosis of SARS-CoV-2 Pneumonia. Diagnostics (Basel). 2021;11(7). https://doi.org/10.3390/diagnostics11071270.

3. China TNHCotPsRo. Diagnosis and Treatment Protocol for COVID-19 (Trial Version 6) 2020 [cited; Available from: http://www.gov.cn/zhengce/zhengceku/2020-02/19/content_5480948.htm.

4. Ye Q, Wang B, Mao J. The pathogenesis and treatment of the 'Cytokine Storm' in COVID-19. J Infect. 2020;80(6):607-13. https://doi.org/10.1016/j.jinf.2020.03.037.

5. Arabi YM, Mandourah Y, Al-Hameed F, Sindi AA, Almekhlafi GA, Hussein MA, et al. Corticosteroid Therapy for Critically III Patients with Middle East Respiratory Syndrome. Am J Respir Crit Care Med. 2018;197(6):757-67. https://doi.org/10.1164/rccm.201706-1172oc.

6. Mattos-Silva P, Felix NS, Silva PL, Robba C, Battaglini D, Pelosi P, et al. Pros and cons of corticosteroid therapy for COVID-19 patients. Respir Physiol Neurobiol. 2020;280:103492.

https://doi.org/10.1016/j.resp.2020.103492.

7. Xu K, Chen Y, Yuan J, Yi P, Ding C, Wu W, et al. Factors Associated With Prolonged Viral RNA Shedding in Patients with Coronavirus Disease 2019 (COVID-19). Clin Infect Dis. 2020;71(15):799-806. https://doi.org/10.1093/cid/ciaa351.

8. Ling Y, Xu SB, Lin YX, Tian D, Zhu ZQ, Dai FH, et al. Persistence and clearance of viral RNA in 2019 novel coronavirus disease rehabilitation patients. Chin Med J (Engl). 2020;133(9):1039-43. https://doi.org/10.1097/cm9.0000000000000774.

9. Li TZ, Cao ZH, Chen Y, Cai MT, Zhang LY, Xu H, et al. Duration of SARS-CoV-2 RNA shedding and factors associated with prolonged viral shedding in patients with COVID-19. J Med Virol. 2021;93(1):506-12. https://doi.org/10.1002/jmv.26280.

10. Chen X, Zhu B, Hong W, Zeng J, He X, Chen J, et al. Associations of clinical characteristics and treatment regimens with the duration of viral RNA shedding in patients with COVID-19. Int J Infect Dis. 2020;98:252-60. https://doi.org/10.1016/j.ijid.2020.06.091.

11. Fu E, Ma R, Wang L, Fu H, Li W. Study on clinical characteristics of 173 cases of COVID-19 and effect of glucocorticoid on nucleic acid negative conversion. Am J Transl Res. 2021;13(5):4251-65.

12. Fu HY, Luo Y, Gao JP, Wang L, Li HJ, Li X, et al. Effects of Short-Term Low-Dose Glucocorticoids for Patients with Mild COVID-19. Biomed Res Int. 2020;2020:2854186. https://doi.org/10.1155/2020/2854186.

13. Group RC, Horby P, Lim WS, Emberson JR, Mafham M, Bell JL, et al. Dexamethasone in Hospitalized Patients with Covid-19. N Engl J Med. 2021;384(8):693-704. https://doi.org/10.1056/nejmoa2021436.

14. Wang Y, Jiang W, He Q, Wang C, Wang B, Zhou P, et al. A retrospective cohort study of methylprednisolone therapy in severe patients with COVID-19 pneumonia. Signal Transduct Target Ther. 2020;5(1):57. https://doi.org/10.1038/s41392-020-0158-2.

15. Li X, Yang Y, Liu L, Yang X, Zhao X, Li Y, et al. Effect of combination antiviral therapy on hematological profiles in 151 adults hospitalized with severe coronavirus disease 2019. Pharmacol Res. 2020;160:105036. https://doi.org/10.1016/j.phrs.2020.105036.

16. Fu Y, Han P, Zhu R, Bai T, Yi J, Zhao X, et al. Risk factors for viral RNA shedding in COVID-19 patients. Eur Respir J. 2020;56(1). https://doi.org/10.1183/13993003.01190-2020.

17. Hu X, Xing Y, Jia J, Ni W, Liang J, Zhao D, et al. Factors associated with negative conversion of viral RNA in patients hospitalized with COVID-19. Sci Total Environ. 2020;728:138812.

https://doi.org/10.1016/j.scitotenv.2020.138812.

Page $8 / 14$ 
18. Young BE, Ong SWX, Ng LFP, Anderson DE, Chia WN, Chia PY, et al. Viral dynamics and immune correlates of COVID-19 disease severity. Clin Infect Dis. 2020 August 28. https://doi.org/10.1093/cid/ciaa1280.

19. Carmo A, Pereira-Vaz J, Mota V, Mendes A, Morais C, da Silva AC, et al. clearance and persistence of SARS-CoV2 RNA in patients with COVID-19. J Med Virol. 2020;92(10):2227-31. https://doi.org/10.1002/jmv.26103.

20. de Vries M, Mohamed AS, Prescott RA, Valero-Jimenez AM, Desvignes L, O'Connor R, et al. A comparative analysis of SARS-CoV-2 antivirals in human airway models characterizes 3CL(pro) inhibitor PF-00835231 as a potential new treatment for COVID-19. bioRxiv. 2021 February 19. https://doi.org/10.1101/2020.08.28.272880.

21. Alam S, Sarker MMR, Afrin S, Richi FT, Zhao C, Zhou JR, et al. Traditional Herbal Medicines, Bioactive Metabolites, and Plant Products Against COVID-19: Update on Clinical Trials and Mechanism of Actions. Front Pharmacol. 2021;12:671498. https://doi.org/10.3389/fphar.2021.671498.

\section{Tables}

Table 1. Characteristics of Patients Receiving or Not Receiving corticosteroid, before and after Propensity-Score Matching. 
Characteristic

Unmatched Patients

\section{No}

dexamethasone $(\mathrm{N}=347)$

Nucleic acid negative $28.00(22.00-35.00)$

(days $₫$ conversion

time

Days lag from illness 10.00 (7.00-15.00) onset to hospital

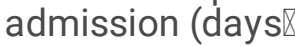

Age (years)

56.98 (13.78)

Gender (Male,\%)

177 (51.01)

Past diagnoses-no.

Complication (\%)

None
$\begin{aligned} & \text { Combined with } 1 \\ & \text { diseases }\end{aligned}$
$\begin{aligned} & \text { Combined with } 2 \\ & \text { diseases }\end{aligned}$
Combined with 3 or
more than 3 diseases

Comorbidities upon admission (\%)

\begin{tabular}{lllll} 
Hypertension & $53(15.27)$ & $20(19.05)$ & $3(11.54)$ & $2(15.38)$ \\
\hline $\begin{array}{l}\text { Coronary artery } \\
\text { disease }\end{array}$ & $15(4.32)$ & $1(0.95)$ & $0.00(0.00)$ & $0.00(0.00)$ \\
\hline Diabetes & $29(8.36)$ & $11(10.48)$ & $3(11.54)$ & $0(0.00)$ \\
\hline $\begin{array}{l}\text { Other endocrine } \\
\text { system disease }\end{array}$ & $5(1.44)$ & $5(4.76)$ & $1(3.23)$ & $1(3.23)$ \\
\hline $\begin{array}{l}\text { Digestive system } \\
\text { disease }\end{array}$ & $12(3.46)$ & $6(5.71)$ & $1(3.85)$ & $0(0.00)$ \\
\hline $\begin{array}{l}\text { Maglignant tumor } \\
\text { Respiratory system } \\
\text { disease }\end{array}$ & $8(2.31)$ & $6(5.71)$ & $2(7.69)$ & $0(0.00)$ \\
\hline $\begin{array}{l}\text { Signs and Symptoms } \\
\text { at admission (\%) }\end{array}$ & $284(81.84)$ & $5(4.76)$ & $2(7.69)$ & $0(0.00)$ \\
\hline $\begin{array}{l}\text { Fever } \\
\text { Cough }\end{array}$ & $239(68.88)$ & $91(86.67)$ & $20(76.92)$ & $11(84.62)$ \\
\hline $\begin{array}{l}\text { Sputum } \\
\text { Myalgia }\end{array}$ & $85(24.50)$ & $77(73.33)$ & $16(61.54)$ & $7(53.85)$ \\
\hline
\end{tabular}

matched Patients

dexamethasone $(\mathrm{N}=105) \quad$ No corticosteroid

Corticosteroid $\quad(\mathrm{N}=13)$ $(\mathrm{N}=26)$

$\begin{array}{ll}28.00(23.25- & 23.00(14.00- \\ 34.00) & 34.00)\end{array}$

$10.00(7.00-14.00)$

$\begin{array}{ll}12.00(7.00- & 10.00(9.00- \\ 15.00) & 12.00)\end{array}$

$59.88(10.41) \quad 60.46(12.97)$

$9(34.62) \quad 4(30.77)$
255 (73.49)

$47(13.54)$

$31(8.93)$

$14(4.03)$

$7(6.67)$
19 (73.08)

22 (20.95)

$10(9.52)$

$2(7.69)$
10 (76.92)
$2(7.69) \quad 0(0.00)$

$0(0.00)$

$3(23.08)$

$2(7.69) \quad 0(0.00)$

$3(11.54) \quad 3(23.08)$

$2(7.69) \quad 0(0.00)$
more than 3 diseases 


\begin{tabular}{|c|c|c|c|c|}
\hline Fatigue & 155 (44.67) & $57(54.29)$ & $9(34.62)$ & $6(46.15)$ \\
\hline Diarrhea & $52(14.99)$ & $15(14.29)$ & $3(11.54)$ & $0(0.00)$ \\
\hline Nausea or vomiting & $39(11.24)$ & $24(22.86)$ & $6(23.08)$ & $0(0.00)$ \\
\hline \multicolumn{5}{|l|}{ Laboratory test } \\
\hline $\begin{array}{l}\text { Leucocytes }\left(\times 10^{9} / \mathrm{L} ;\right. \\
\text { normal range 3.5-9.5) }\end{array}$ & $5.91(2.01)$ & $6.53(2.73)$ & $6.53(2.83)$ & $6.09(1.80)$ \\
\hline $\begin{array}{l}\text { Lymphocytes }\left(\times 10^{9} / \mathrm{L} \text {; }\right. \\
\text { normal range } 1.1-3.2)\end{array}$ & $1.44(0.62)$ & $1.14(0.48)$ & $\begin{array}{l}1.09(0.84- \\
1.59)\end{array}$ & $\begin{array}{l}1.36(1.16- \\
1.64)\end{array}$ \\
\hline $\begin{array}{l}\text { Monocyte }\left(\times 10^{9} / \mathrm{L} ;\right. \\
\text { normal range } 0.1-0.6)\end{array}$ & $0.43(0.33-0.54)$ & $0.40(0.27-0.56)$ & $\begin{array}{l}0.46(0.30- \\
0.52)\end{array}$ & $\begin{array}{l}0.54(0.37- \\
0.58)\end{array}$ \\
\hline $\begin{array}{l}\text { Neutrophils }\left(\times 10^{9} / \mathrm{L} ;\right. \\
\text { normal range } 1.8-6.3)\end{array}$ & $3.67(2.70-4.65)$ & $4.57(3.32-6.20)$ & $\begin{array}{l}4.29(2.87- \\
5.83)\end{array}$ & $\begin{array}{l}3.86(3.38- \\
4.57)\end{array}$ \\
\hline $\begin{array}{l}\text { Haemoglobin }(\mathrm{g} / \mathrm{L} ; \\
\text { normal range } 130.0- \\
175.0)\end{array}$ & $126.88(17.20)$ & $121.83(19.45)$ & $\begin{array}{l}121.04 \\
(15.91)\end{array}$ & $120.85(8.63)$ \\
\hline $\begin{array}{l}\text { Platelets }\left(\times 10^{9} / \mathrm{L} \text {; }\right. \\
\text { normal range } 125.0- \\
350.0)\end{array}$ & $228.74(78.51)$ & $232.01(100.40)$ & $\begin{array}{l}239.81 \\
(89.90)\end{array}$ & $\begin{array}{l}262.92 \\
(57.88)\end{array}$ \\
\hline Albumin (g/L) & $34.67(6.31)$ & $31.11(4.99)$ & $34.00(4.31)$ & $33.64(3.16)$ \\
\hline $\begin{array}{l}\text { Alanine } \\
\text { aminotransferase }\end{array}$ & $32.00(20.00-49.00)$ & $33.00(20.00-49.00)$ & $\begin{array}{l}29.00(17.75- \\
39.75)\end{array}$ & $\begin{array}{l}29.00(20.00- \\
46.00)\end{array}$ \\
\hline \multicolumn{5}{|l|}{$\begin{array}{l}(\mathrm{U} / \mathrm{L} ; \text { normal range } \\
5-40)\end{array}$} \\
\hline $\begin{array}{l}\text { Serum creatinine } \\
\text { ( } \mu \mathrm{mol} / L \text {; normal } \\
\text { range 44-106) }\end{array}$ & $69.00(47.00-104.75)$ & $73.00(41.00-139.00)$ & $\begin{array}{l}67.00(47.25- \\
91.00)\end{array}$ & $\begin{array}{l}52.00(47.00- \\
111.00)\end{array}$ \\
\hline Missing data (\%) & $9(2.59)$ & $4(3.8)$ & & \\
\hline $\begin{array}{l}\text { High sensitivity } \\
\text { cardiac troponin I }\end{array}$ & $2.80(1.50-7.20)$ & $3.70(2.00-9.40)$ & $\begin{array}{l}2.40 \\
5.42)\end{array}$ & $\begin{array}{l}2.70(1.50- \\
3.60)\end{array}$ \\
\hline \multicolumn{5}{|l|}{$\begin{array}{l}\text { (ng/L; normal range } \\
<26.2 \text { ) }\end{array}$} \\
\hline Missing data (\%) & 124(35.73) & $24(22.86)$ & 0 & 0 \\
\hline $\begin{array}{l}\text { Prothrombin time (s, } \\
\text { normal range11.0- } \\
16.0)\end{array}$ & $13.69(6.62)$ & $13.26(1.18)$ & $14.42(7.34)$ & 13.08 (1.33) \\
\hline Missing data (\%) & 11(3.17) & $2(1.90)$ & 0 & 0 \\
\hline $\begin{array}{l}\text { D-dimer }(\mathrm{mg} / \mathrm{L} ; \\
\text { normal range<0.5) }\end{array}$ & $0.40(0.19-0.88)$ & $0.66(0.34-1.45)$ & $\begin{array}{l}0.34(0.23- \\
0.64)\end{array}$ & $\begin{array}{l}0.45(0.35- \\
0.66)\end{array}$ \\
\hline Missing data (\%) & 12(3.49) & $2(1.9)$ & 0 & 0 \\
\hline $\begin{array}{l}\text { Interleukin-6 (pg/ml; } \\
\text { normal range 0.0-7.0) }\end{array}$ & $2.11(1.50-4.34)$ & $3.05(1.50-8.86)$ & $\begin{array}{l}2.33(1.50- \\
6.84)\end{array}$ & $\begin{array}{l}2.87(1.72- \\
12.88)\end{array}$ \\
\hline
\end{tabular}




\begin{tabular}{|c|c|c|c|c|}
\hline Missing data (\%) & $109(31.41)$ & $28(26.67)$ & 0 & 0 \\
\hline $\begin{array}{l}\text { Procalcitonin }(\mu \mathrm{g} / \mathrm{L} \text {; } \\
\text { normal range }<0.50)\end{array}$ & $0.05(0.04-0.08)$ & $0.06(0.04-0.13)$ & $\ddagger$ & $\ddagger$ \\
\hline Missing data (\%) & $22(6.34)$ & $2(1.9)$ & 0 & 0 \\
\hline Anaemia (\%) & $25(7.20)$ & $8(7.62)$ & $1(3.85)$ & $1(7.69)$ \\
\hline \multicolumn{5}{|l|}{ CT findings (\%) } \\
\hline $\begin{array}{l}\text { Lung consolidation } \\
\text { shadow }\end{array}$ & $150(43.23)$ & $60(57.14)$ & $11(42.31)$ & $6(46.15)$ \\
\hline $\begin{array}{l}\text { Ground glass } \\
\text { shadow }\end{array}$ & $314(90.49)$ & $90(85.71)$ & $23(88.46)$ & $13(100.00)$ \\
\hline Hydrothorax & $21(6.05)$ & $7(6.67)$ & $0(0.00)$ & $1(7.69)$ \\
\hline $\begin{array}{l}\text { Hilar node } \\
\text { enlargement }\end{array}$ & $25(7.20)$ & $4(3.81)$ & $3(11.54)$ & $1(7.69)$ \\
\hline Double lung lesions & $337(97.12)$ & $103(98.10)$ & $30(96.77)$ & $30(96.77)$ \\
\hline \multicolumn{5}{|l|}{ Treatment (\%) } \\
\hline Remdesivir & 39 (11.24) & $24(22.86)$ & $2(7.69)$ & $4(30.77)$ \\
\hline Arbidol & $330(95.10)$ & 99 (94.29) & $25(96.15)$ & $13(100.00)$ \\
\hline $\begin{array}{l}\text { Lianhua Qingwen } \\
\text { Capsule }\end{array}$ & 247 (71.18) & 78 (74.29) & $22(84.62)$ & $9(69.23)$ \\
\hline Chloroquine & $43(12.39)$ & $20(19.05)$ & $3(9.68)$ & $7(22.58)$ \\
\hline Immune globulin & $34(9.80)$ & $21(20.00)$ & $3(11.54)$ & $2(15.38)$ \\
\hline Thymosin & $206(59.37)$ & 79 (75.24) & $20(76.92)$ & $7(53.85)$ \\
\hline Antibiotics & 304 (87.61) & 98 (93.33) & $23(88.46)$ & $11(84.62)$ \\
\hline Plasbumin & $19(5.48)$ & $13(12.38)$ & $3(9.68)$ & $3(9.68)$ \\
\hline $\begin{array}{l}\text { Enteral } \\
\text { nutritionalemulsion }\end{array}$ & $34(9.80)$ & $14(13.33)$ & $4(12.90)$ & $3(9.68)$ \\
\hline Parenteral nutrition & $20(5.76)$ & $8(7.62)$ & $2(6.45)$ & $1(3.23)$ \\
\hline nutrition supplement & $56(16.14)$ & $26(24.76)$ & $8(25.81)$ & $6(19.35)$ \\
\hline \multicolumn{5}{|c|}{ kinds of nutrition supplement (\%) } \\
\hline No & $291(83.86)$ & $79(75.24)$ & $23(74.19)$ & $25(80.65)$ \\
\hline 1 kind & $42(12.10)$ & $17(16.19)$ & $7(22.58)$ & $5(16.13)$ \\
\hline 2 and more kinds & $14(4.03)$ & $9(8.57)$ & $1(3.23)$ & $1(3.23)$ \\
\hline Nasal catheters & $342(98.56)$ & $101(96.19)$ & $1.00(0.00)$ & $1.00(0.00)$ \\
\hline Mask and high flow & $35(10.09)$ & $31(29.52)$ & $2(7.69)$ & $0(0.00)$ \\
\hline Invasive ventilator & $5(1.44)$ & $5(4.76)$ & $0.00(0.00)$ & $0.00(0.00)$ \\
\hline
\end{tabular}


Continuous variables are presented as mean (SD) or median (IQR), categorical variables are presented as number (percentage).

$\ddagger$ matched in concentration levels

Table2 The correlation between corticosteroid and the time of Covid-19 clearance by multivariate piecewise linear regression model in unmatched persons

\begin{tabular}{|lll|}
\hline Exposure & $\begin{array}{l}\text { Model I† } \\
\beta(95 \% \mathrm{Cl}) \text { Pvalue }\end{array}$ & $\begin{array}{l}\text { Model II } \\
\beta(95 \% \mathrm{Cl}) \text { Pvalue }\end{array}$ \\
\hline No Lianhua Qingwen Capsule & & \\
\hline Corticosteroid & & Ref. \\
\hline No & Ref. & $5.37(-4.88,15.62) 0.318$ \\
\hline Yes & $-0.00(-4.51,4.50)$ & 0.999 \\
\hline Lianhua Qingwen Capsule & & \\
\hline Corticosteroid & & Ref. \\
\hline No & Ref. & $-4.77(-9.41,-0.12) 0.047$ \\
\hline Yes & $-3.52(-9.36,2.33)$ & 0.239 \\
\hline
\end{tabular}

† Adjusted for gender and age

‡ Adjusted for gender, age, days lag from illness onset

to hospital admission Complication, sputum, myalgia, Remdesivir, Arbidol, plasbumin, mask and high flow, white blood cell count, lymphocyte, anaemia, albumin, ALT, D-dimer, IL-6, lung consolidation shadow, ground glass shadow, hydrothorax, fever, cough, hypertension, diabetes, maglignant tumor, monocyte, procalcitonin, coronary artery disease, digestive system disease, other endocrine system disease, high sensitivity cardiac troponin I

Table 3 The correlation between corticosteroid and the time of Covid-19 clearance by multivariate piecewise linear regression model in matched persons

\begin{tabular}{|lll|}
\hline Exposure & No Lianhua Qingwen Capsule & Lianhua Qingwen Capsule \\
\hline Corticosteroid & & \\
\hline No & Ref. & Ref \\
Yes & $7.99(-2.12,18.11) 0.182^{\star}$ & $-8.61(-16.73,-0.50) 0.047^{\star}$ \\
\hline
\end{tabular}

*Adjust model adjust for: propensity score

\section{Figures}




\section{Image not available with this version}

Figure 1

Additional multivariable propensity-score analyses yielded consistent results with the unmatched participants (Figure 1)

\section{Supplementary Files}

This is a list of supplementary files associated with this preprint. Click to download.

- supplementtables.doc 